\section{Research and Teaching as Actions Supporting the Specificity of a Territory: Developing a Design and Pedagogic Strategy for the Abandoned Mining Landscapes of Sardinia}

Pier Francesco Cherchi

University of Cagliari

\section{Marco Lecis \\ University of Cagliari}

\section{Marco Moro}

University of Cagliari
This paper illustrates a case study of teaching and research applied to the abandoned mining landscapes of the Sulcis area, located in the south-east side of Sardinia, one of the poorest in Europe. Although the region's critical condition in the present, the area is nevertheless extremely rich in fascination and history. It offers unique natural landscapes, mostly pristine, a variety of archeological sites and, as mentioned, the ruins of the mining installations. All of this makes foreseeable a concrete possibility of regeneration for the area, based on tourism, one of the island primary resources. The local institutions of Sulcis started a partnership with the University of Cagliari aiming to pursuit not just a practical and economical outcome in the immediate present, more a cultural and deeper rescue with a wider perspective. In the following pages, we present our academic activities in this mark and how we managed to guarantee fruitful superpositions of pedagogy, design, and research in our work within this kind of cooperation.

Our focus is, therefore, the relationship between researching and teaching activities and the actions in support of the territory, pursued in a joint venture with the political institution. During these experiences, we defined a strategy to intercross these different layers, bringing the real and concrete dimension into our classroom, sharing our work with the students, and, at the same time, transferring the fruits of the teaching experiences to the territory. The correspondence between these two levels is not free of ambiguity and contradictions, however, we are convinced that it might show very important and fruitful outcomes.

As design professors of the Architecture School of Cagliari, we live a condition that we believe is a special and interesting case study. A condition that at first sight might appear a limitation, whilst it also proved to be an opportunity and it offered the chance to experiment with innovative research tools and teaching methods. The school is located in Sardinia, a poor territory and above all an island, a place that strives every day with the difficulties of physical communication with the outside world and that it has introjected this condition from its past and the character of its cultures. A condition of isolation that led people who are responsible for the social and economic growth of territory, to address questions of main relevance to the local university community in the past few years. Therefore, the concrete management of the territory and the studying and teaching activity converged and intertwined in the design studios attracting real-world problems presented by the political, social and economic reality of the territory. Keeping together the different areas, making the fields of concrete cases and teaching converge while maintaining the specificity and coherence of the actions developed, is a difficult but stimulating task that we've been tackling in the last ten years.

From the beginning, it seemed clear that the contribution of the school to the urgencies of the territory, despite the cultural and scientific approach, should not merely involve small groups of researchers and professors. On the contrary, the idea was of an expanded experience, which would integrate concrete proposals elaborated with mature designers, with new reflections and debates about the adequate and pertinent solutions to be given in front of specific topics, open to the student community in design studios, lectures and workshops. A challenge of openness that is currently 


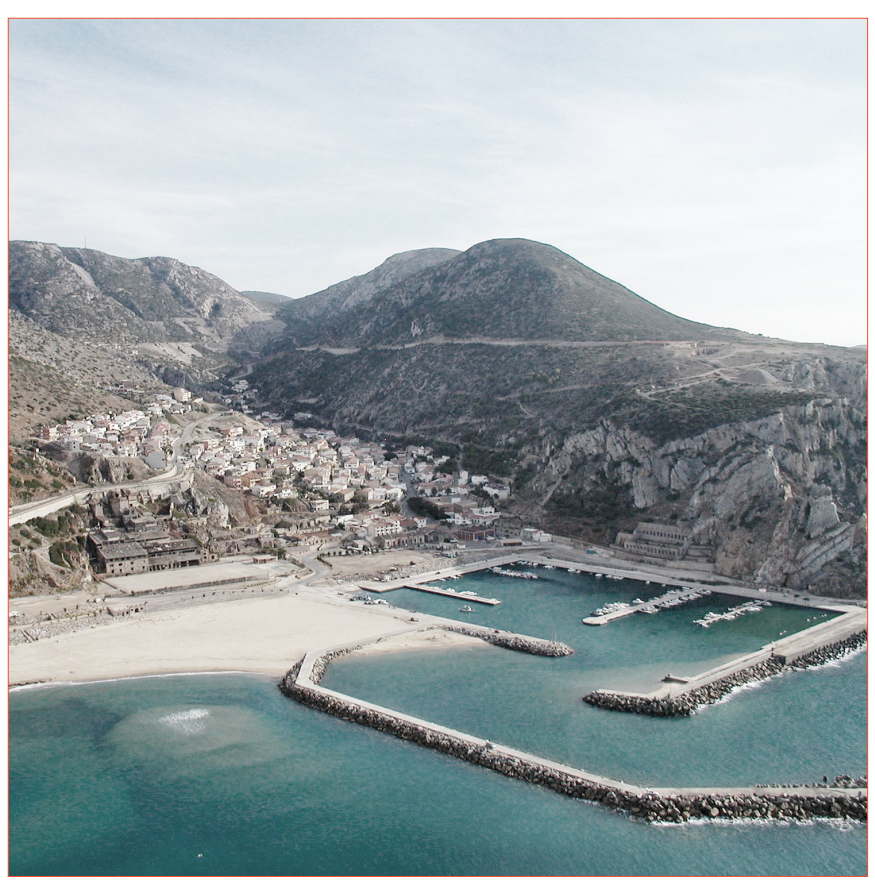

Figure 1. An image of the coastal view of Buggerru. The mining village is set in a narrow and deep valley that opens right to the sea. At both sides of the port (built only recently, in the 90s) are visible the large ruins of the Laveria Malfitano and

requiring multi-level coordination of actions and verifications of the effectiveness of results, so that the development of new methodologies and new architectural teaching formulas appears as a necessary condition.

\section{INTEGRATION BETWEEN RESEARCH-BY-DESIGN AND TEACHING LEVELS}

The practice-based design research opportunities, developed in frail and sensitive contexts, forced the pedagogical and didactic process to formulate new strategies for the transmission of the architectural discipline. Initially, the complexity of the topics raised some questions about the possibility of being effective in architectural pedagogy in the undergraduate second-year studios. However, we decided not to separate the levels, the research one and the teaching design as a discipline one. For this purpose, the strategy adopted provides two main actions, based on the idea of simplification and fragmentation. Firstly, classes made up of ninety students, were divided into small teams composed by two or three students, in turn grouped into macro-groups of six. This set-up allowed the teaching staff - composed of two professors and five assistants - to manage a large number of students, simplifying and guaranteeing constant interaction between teacher and student during the whole design process.

Associated with this organization of the studio, has been established a radical and sophisticated idea of design operation, according to the logic of small interventions coordinated each one with each other. In the case that we illustrate, the regeneration of the mining and coastal village of Buggerru, the strategy focused on the distribution of small interventions placed in significant positions, and for this reasonable of reconfiguring the place and the landscape thanks to punctual modifications, rather than totalizing actions that replace the existing environment and set a new beginning. We named this strategy "designing by constellations", a philosophy of intervention based on small-scale, low-density, separate and in mutual tension insertions.

\section{TESTING METHODOLOGIES OF INTERVENTIONS AND TEACHING EXPERIENCES IN A SIGNIFICANT CASE STUDY: THE WATERFRONT OF BUGGERRU, A FORMER MINING VILLAGE.}

One of the most significant cases, in which the above-mentioned conditions of collaboration and convergence between the real urgencies of the territory and the research and teaching tasks produced significant results, is the case of study of Buggerru. Buggerru is a former mining village, located in Sulcis, the south-western area of Sardinia, one of the poorest regions in Europe: a condition that derives from the crisis that has marked its main industrial economic sector since the late '70s. The region, one of the least inhabited in the Italian territory, has developed since the mid-nineteenth century, with the beginning of the intensive exploitation of its mineral deposits.

Sulcis is a territory rich in fascination and history, one of the wildest and most striking of the second-largest island of the Mediterranean. This portion of land, developed with a varied profile along seventeen kilometers between the coastal landings of Funtanamare and Buggerru, as well as for the uniqueness of landscaping, constitutes the limit of a territory geologically marked by significant mineral resources. During the thirties, the fascist regime invested heavily in this territory planning a sequence of mining sites and founding a whole city, Carbonia, inaugurated by Mussolini in 1938. However, the post-war period is marked by the crisis of mining activity initiating a process of slow abandonment, orphaning an area that had been designed and populated at the service of the territory. Nowadays, the same territory appears, under its history, deeply wounded even in its natural resources, degraded and affected by pollution.

Among the various former mining sites and villages of Sulcis, Buggerru has a specific history: it was founded in 1865 on the southwest coast of Sardinia and was the operational headquarter of the Sociétè Anonyme des Mines de Malfidano, based in Paris. A small elite, formed by the leaders of the company, transformed the inhabited portion of the Sardinian territory into a very lively center, equipped, from the beginning of the century, with a cinema, a theatre, and other social facilities. From the middle to the end of the nineteenth century the village rapidly expanded, while during the new century the inflection and a deep crisis begun. In the sixties, the mining activity became progressively anti-economic and in 1977 the plant was closed. After more than a century, the village has seen its population decreasing and today it counts approximately a thousand inhabitants. In the eighties, the construction of a new port addressed hopes and dreams of a new prosperous future. Due to a very shortsighted political and economic planning, after a few years from the opening, the port progressively slowed down its activity. Today, even the sand has invaded the harbor significantly reducing its functionality. Today, a new mayor 


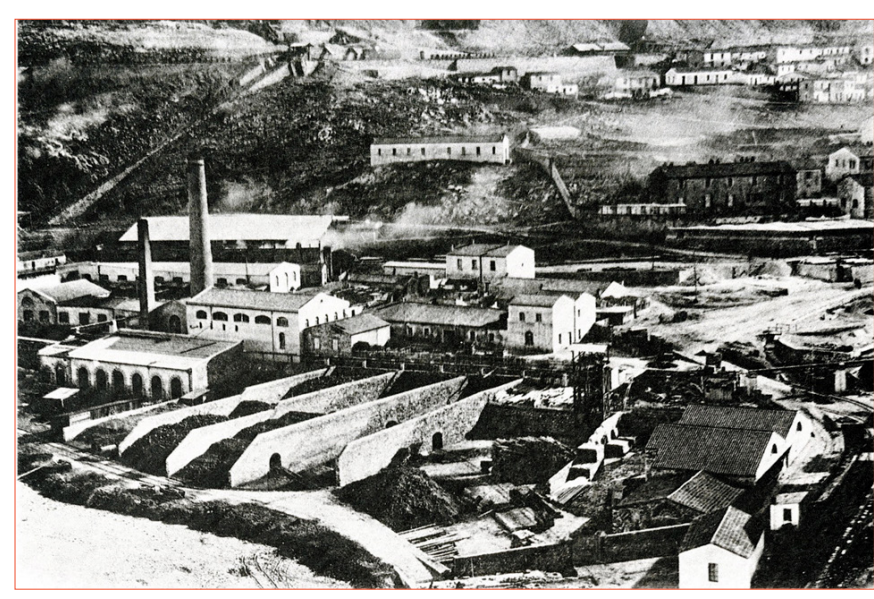

Figure 2. A historic view of the waterfront of Buggerru. This picture from the beginning of the XX century shows how the area of the actual beach and port was not intended as an urban facility: the site was completely occupied by the mine infrastructures and was separated from the village inhabitants life.

and new investments seem to address the future in the right direction. Our study, research, and didactic activity is meant as a concrete contribution in this direction.

In 2018 we began a collaboration with the major of Buggerru, who commissioned our team to study a masterplan for the regeneration of the waterfront of the village. We are working on the masterplan with a team of architects, researchers, and other disciplines advisors. Meanwhile, we also propose the same themes in the design studio, as a design exercise for students. The relationship between these two levels is not direct and we have studied a strategy that could allow us to develop the same themes on different planes.

Our pedagogic approach developed on the idea of simplification and fragmentation, a strategy of "designing by constellations", a philosophy of intervention based on small-scale, low-density, separate and in mutual tension insertions. We believe that this strategy is both a concrete way to intervene on the territory and a teaching formula. As a first step, starting from the analysis and characteristic of the sites, we noticed the opportunity of developing and testing a design philosophy and methodology, that we are now using to support the major with our team of architects. On the other side, we identified the teaching goals that this methodology could offer and we developed a sequence of exercises that allowed our students to join our perspective and to work adopting the same strategy.

Buggerru - and Sulcis in general - are very fragile areas. They maintain traces of their histories - also the tragical ones - in the magnificent frame of the natural landscape. Referring to this condition, we decided that the proper way to intervene it was not a macro design approach, coming from the outside, which might impose new orders and forms over a delicate and harsh landscape. On the contrary, we thought that the beauty of these sites is their weakness, their fragility, their precarious equilibrium between nature and history: so we noticed a different way of intervening, one which could be sensitive, discreet and capable of interpreting its deep wefts.

Our strategy was then determined by the intention of acting with careful and localized interventions, at the minimum scale and with extremely low density. We imagined groups of architectural interventions that could present themselves as a constellation, a set of analogs but not homologs architectures. A constellation is not a series because the relationship between its pieces is not mechanical or repetitive. A constellation is neither a system because it lacks logical or strictly formal connections. The constellation, from our perspective, is a group of different pieces, heterogeneous, separated and diffused, that enter in tension each other and, due to the openness and variety of the set they form. These pieces are conceived as parts of a whole, bringing the strength of redefining and regenerating an area freeing the project from the obligation of redesigning and modifying every single part, whilst acting through a set of isolated and widespread points.

We introduced the concept of constellation to our student using art and architectural references, among them three emerge and describe effectively the philosophy: the first is Zeichen in Gelb, Characters in yellow, from 1937, a painting by Paul Klee, in which it can be noticed a kind of writing, formed by a series of tiny black signs. The most important thing in the picture are not those signs, but the areas that separate them: those colored areas - yellow, orange and red - render with evidence the tension between the sings and enliven the whole with the energy of their color. The properties of a constellation in this picture are generated and made evident by the areas between the sings. A second reference that we proposed to students was a draft of Le Corbusier for the Chandigarh acropolis. Here again, we have the monumental interventions, marked in red. But we all know that the architecture of this institutional site is determined by the empty spaces, the distances between the monuments matters as much as the masses and their volumes and the emblematic facades. The last reference was the Bernard Tschumi design for the Parc de la Villette in Paris, where a regular grid of tiny and separated interventions, the follies, is superposed onto a series of different levels.

Once the strategy was presented to students, we started the development of a series of exercises stimulating the awareness to the design approach we were proposing. With this goal, we studied a sequence of exercises divided into three phases: the first one was called "Settlement strategies", the second "One principle problem", the third "How to build a constellation".

As mentioned before we divided our students into macro groups of six, each one subdivided into three couples. Every macro group was then in charge of the design of one constellation while each couple must develop a single piece. The first and the third phases were collective, engaging all six members, instead, during the second phase, students worked in couples.

The first exercise, "Settlement Strategies", forced the students to define a territorial strategy for their constellation. Working on a zenithal photo of the area - the coastal front 


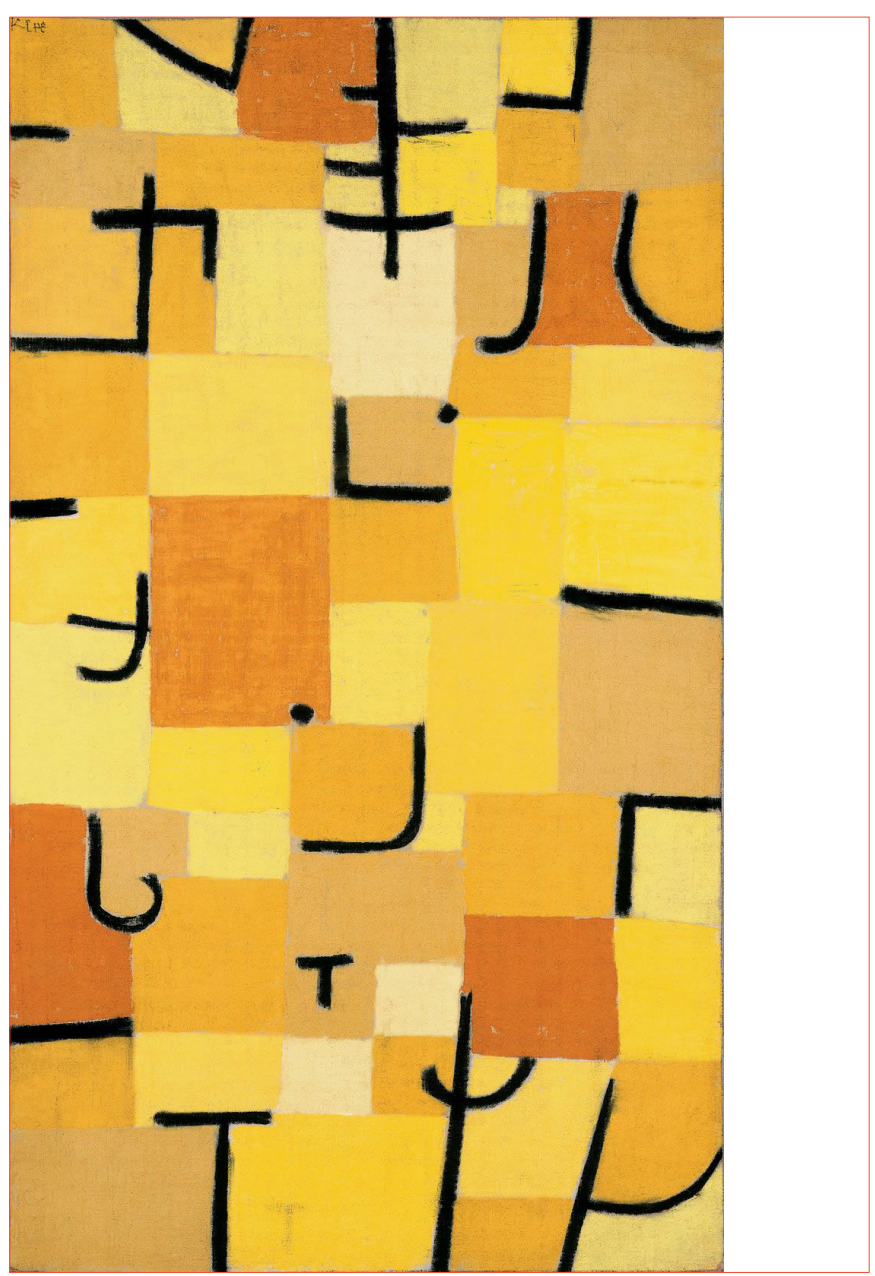

Figure 3. Paul Klee, Zeichen in Gelb (Characters in yellow), 1937. This is one of the last pictures painted by Klee. We use it to illustrate our concept of

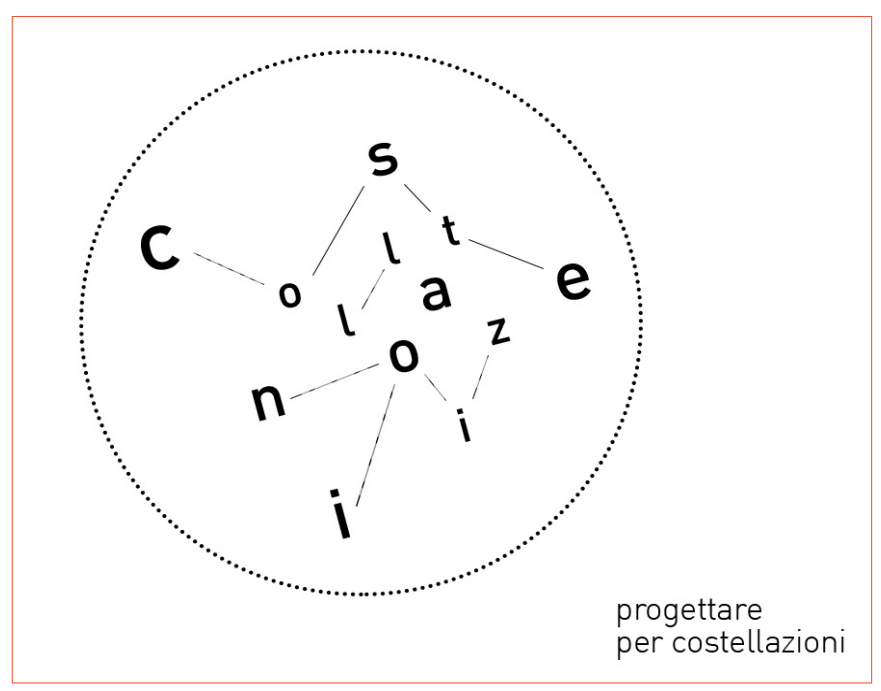

Figure 4. The logo of the design studio: Progettare per Costellazioni, "designing by constellations". of Buggerru - using the collage technique, they had to position a sequence of scattered interventions, as to determine a configuration that they have to describe and argue as a constellation. The exercise was developed entirely during a five hours workshop at the presence and with the support of the teachers. At the end of the available time, each group had to present is work, to discuss it and defend it in front of the others. In this way, without delivering any practical indications, students made their first design approach to the area basing only on the point of view of the constellations: a point of view that puts as preeminent a territorial and urban strategy.

The second phase, "One principle problem", consisted of choosing a specific compositional principle and developing each piece of the constellation according to it. This is a very important passage: since the constellation works with scattered pieces in tension within each other, it is also necessary to establish a form of correspondence between them. We reached this goal by developing every single intervention from a unique formal principle. In this way, we were granted that, as scattered as the piece were, they could, in any case, recalled one to each other.

We decided to reduce the complexity of the exercise proposing only 6 principles, the ones we considered more useful for the area. We presented each principle with three case studies, famous and interesting architecture examples: these case studies had to be different in their final appearance, but all tied by the same formal principle. Once selected a specific principle, students are called to design their piece according to it. No program was given, we didn't define any specific functions in advance, neither we gave the students exact dimensions: we wanted that choices to be taken independently, balancing and setting the correct dimensions and uses starting from their constellation's proper characteristics.

The third and final phase, "How to build a constellation", view the macro group working reunited again. At this time the pieces were already developed, so it was necessary to design the paths and the areas between them, public spaces and other public facilities that might enhance the perception of each set as a working constellation. Only at this moment the constellation was presented as a complete and achieved whole: and this result was realized by only one large format image, a large exploded axonometric view, printed on an $84 \times 84 \mathrm{~cm}$ panel.

Together with this drawing, each macro group also produced three maquettes: one for every single piece, and another large format sheet, representing the pieces in detail. To obtain a coherent and comparable output, we gave a very strict graphic indication.

\section{OUTCOMES OF "DESIGNING BY CONSTELLATION" TEACHING AND INTERVENTION STRATEGY}

In our opinion, a strategy like "designing by constellation" can reach three fundamental goals.

First. Students are allowed to work on themes that are real, concrete opportunities, and not abstract or theoretical academic exercises. This condition offers the possibility to approach a wide range of concrete problems. We worked in close relationship with the major 


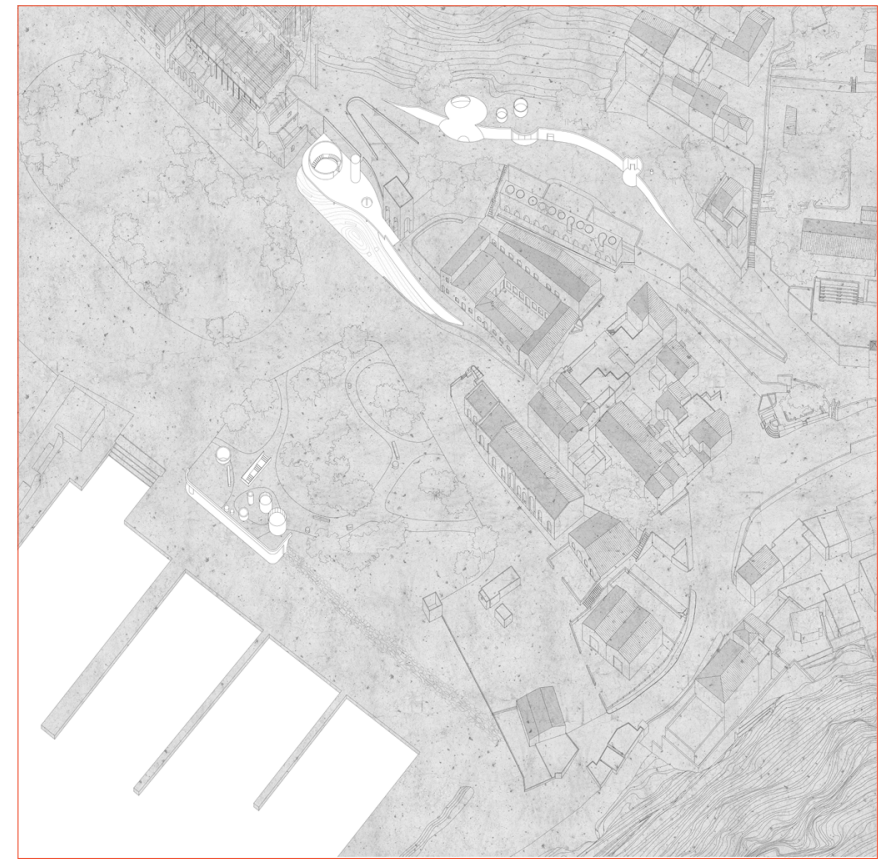

Figure 5. An example of constellation designed by our students for the coastal area of Buggerru. A group of six student design a system of three architectural intervention at the small scale and low density. The compositional principle at the

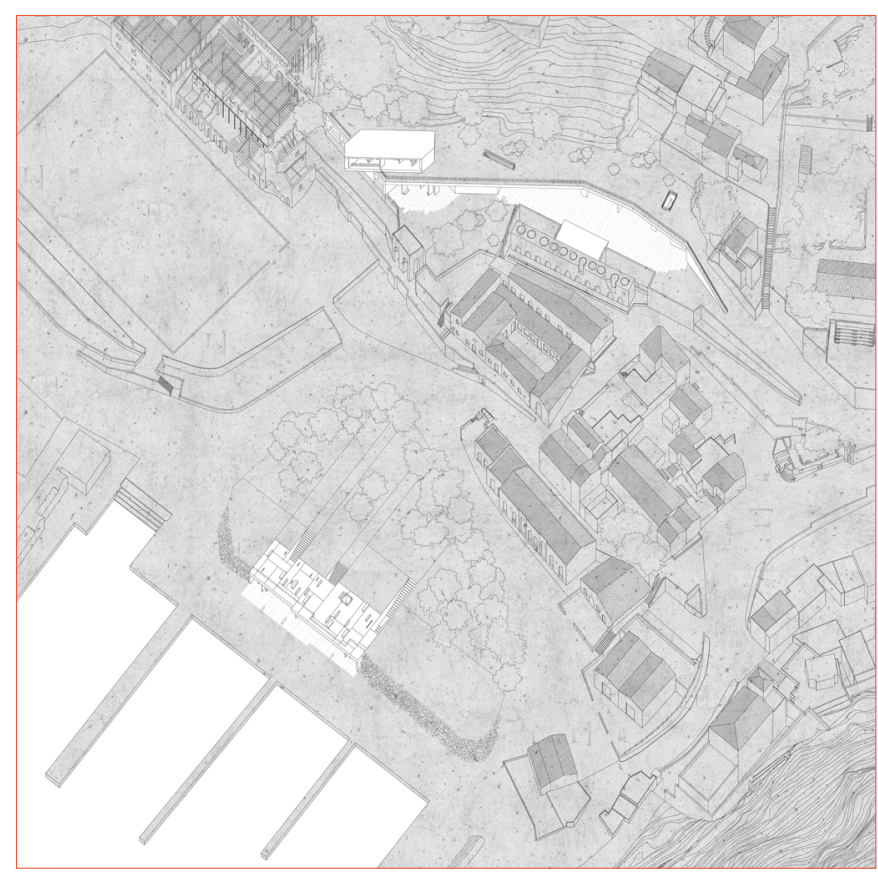

Figure 6. An example of constellation designed by the students for the coastal area of Buggerru. A group of six student design a system of three architectural intervention at the small scale and low density. The compositional principle at the basis of this constellation is the inhabited basement. of Buggerru and his team of architects and engineers: they visited us at the beginning, during and at the end of the semesters, reviewing with the professors the student works. It was a long and attentive process, not free from ambiguity and misunderstanding, with the different levels often shifting and overlapping. But it was very interesting and surely effective for students in developing a mature sense of analysis and awareness on real-world architecture and landscape critical issues.

Second, forcing students to approach their design activity as a teamwork and as a collective activity, in spite of one solipsistic or autoreferential. Every single piece had to be conceived as a part of a wider ensemble, the constellation, and was never considered as an isolated object. This perspective is very important because we are convinced that it can enhance the sensibility to see and perceive the connection that architecture can activate with other building or spaces.

Third, we are interested in two qualities that designing constellation can reveal: openness and integration. An architecture, conceived as a part of a diffuse set, shifts the focus of the architect from the object to the context, from the building to the landscape. We think that the future of our discipline can be played specifically in this field, in the recognition and assumption that we have a great responsibility for the ambient where we are living, and that this engages us beyond designing a single beautiful object.

\section{Bibliography}

Kirova, Tatiana, "Le miniere della Sardegna: dall'ambiente naturale al paesaggio minerario" in L'uomo e le miniere in Sardegna, ed. Anna Saiu Deidda, 79-88, Cagliari: Edizioni della Torre 1993.

Kirova, Tatiana, "Origine e sviluppo degli insediamenti minerari in Sardegna" in L'uomo e le miniere in Sardegna, ed. Anna Saiu Deidda, 89-102, Cagliari: Edizioni della Torre 1993.

Manconi, Francesco, "L'economia e la società delle miniere dall'Unità al Fascismo" in Le miniere e i minatori della Sardegna, ed. Francesco Manconi, 65-80, Milano: Silvana Editrice, 1986.

Manis, Franco, Una miniera: Buggerru, Sassari: Editrice Poddiche, 1980.

Costellazioni. Le parole di Walter Benjamin, ed. Andrea Pinotti, Torino: Einaudi 2018. 